\title{
Chemoprevention in Sporadic Colorectal Cancer: The Role of Salycilates, Nsaids and Coxibs
}

\author{
Manzano A and Pérez-Segura P*
}

Department of Oncology, Hospital Clínico San Carlos, Madrid, Spain

\begin{abstract}
Sporadic colorectal cancer (CRC) represents $75 \%$ of the total of the CRC cases diagnosed and is the second leading cause of cancer death with a a 5-year survival rate of $62 \%$. The development of colorectal cancer is a complex process involving multiple molecular pathways, since the formation of adenomas to the development of carcinoma in the digestive tract (the so-called "adenoma-carcinoma sequence"), in a process that can last several decades. Thus adenomas are considered a surrogate variable for the development of CRC in clinical trials. Although screening strategies (blood in stool, endoscopic and CT-colonoscopy) have supposed a great advance in the early detection of these tumours, they are associated with inconveniences such as their cost and associated morbidity. Moreover screening does not necessarily prevent the development of cancer or prevent mortality. Therefore, interest in primary prevention research has increased in recent years. In this regard, multiple attempts to modify lifestyle and dietary factors to try to reduce the incidence of cancer have been promoted. However, some studies, many of them observational or case-control, have yielded conflicting data. Consequently, in the past 20 years, chemoprevention studies have grown in importance.
\end{abstract}

\section{Introduction}

Sporadic colorectal cancer (CRC) represents $75 \%$ of the total of the CRC cases diagnosed and is the second leading cause of cancer death [1] with a a 5 -year survival rate of $62 \%$ [2].

The development of colorectal cancer is a complex process involving multiple molecular pathways, since the formation of adenomas to the development of carcinoma in the digestive tract (the so-called "adenoma-carcinoma sequence"), in a process that can last several decades [3]. Thus adenomas are considered a surrogate variable for the development of CRC in clinical trials.

Although screening strategies (blood in stool, endoscopic and CTcolonoscopy) have supposed a great advance in the early detection of these tumours, they are associated with inconveniences such as their cost and associated morbidity. Moreover screening does not necessarily prevent the development of cancer or prevent mortality. Therefore, interest in primary prevention research has increased in recent years. In this regard, multiple attempts to modify lifestyle and dietary factors to try to reduce the incidence of cancer have been promoted. However, some studies, many of them observational or case-control, have yielded conflicting data [3]. Consequently, in the past 20 years, chemoprevention studies have grown in importance.

\section{Chemoprevention and molecular pathways}

Cancer chemoprevention is defined as the use of chemical agents in healthy individuals to block, reverse or delay the development of invasive cancer. Although several drugs have been studied, this review focuses on salicylates and non-steroidal anti-inflammatory drugs (NSAIDs), as they constitute a group of agents whose mechanism of action could be directly related to colon cancer chemoprevention. Both treatment groups are inhibitors of the cyclooxygenase (COX) enzyme responsible for the transformation of arachidonic acid to prostaglandins, which are involved in cell proliferation and apoptosis [4] (Figure 1).

In humans, three isoforms of the COX enzyme exists. COX1 is expressed constitutively in all tissues and is involved in maintaining the integrity of the gastric mucosa and platelet aggregation, among other functions. The function of $\mathrm{COX} 3$ remains to be determined, whereas the expression of COX2 is inducible in both inflammatory processes and tumorigenesis. Thus, COX2 is over expressed in colon tumours and adenomas, with expression not observed in normal gastrointestinal mucosa. The mechanism of action of salicylates and NSAIDs as chemopreventive agents are not fully understood, however it is postulated that they act in both COX-dependent and independent mechanisms. In COX-dependent mechanisms, COX inhibition produces a decrease in the levels of prostaglandins and their derivatives (prostacyclins and thromboxane), producing a decrease in the processes involved in cell proliferation. Conversely, COX-dependent mechanisms also lead to an increase in the level of arachidonic acid, which promotes apoptosis by altering mitochondria permeability and could also stimulate the sphingomyelinase enzyme activity that increase ceramide levels (which is known to be a potent inducer of apoptosis). Furthermore, experimental studies have shown that NSAIDs and salicylates induce apoptosis in tissues that do not express the COX enzyme. These COX-independent mechanisms are still being studied, and may be related with the inhibition of the transcription factor NFkB (so genes that are required for cell growth regulation may not be transcribed), and they could also interfere with the peroxisome- $\gamma$ proliferator activated receptor (PPAR) and its ligands, promoting programmed cell death. The COX-independent mechanisms could also interfere with angiogenesis processes necessary for cancer development [4,5] (Figure 2).

*Corresponding author: Pérez-Segura P, Department of Oncology, Hospital Clínico San Carlos, Madrid, Spain, E-mail:pperez.hcsc@salud.madrid.org

Received November 15, 2011; Accepted December 13, 2011; Published December 15, 2011

Citation: Manzano A, Pérez-Segura P (2011) Chemoprevention in Sporadic Colorectal Cancer: The Role of Salycilates, Nsaids and Coxibs. J Cancer Sci Ther S3:005. doi:10.4172/1948-5956.S3-005

Copyright: (C) 2011 Manzano A, et al. This is an open-access article distributed under the terms of the Creative Commons Attribution License, which permits unrestricted use, distribution, and reproduction in any medium, provided the original author and source are credited. 


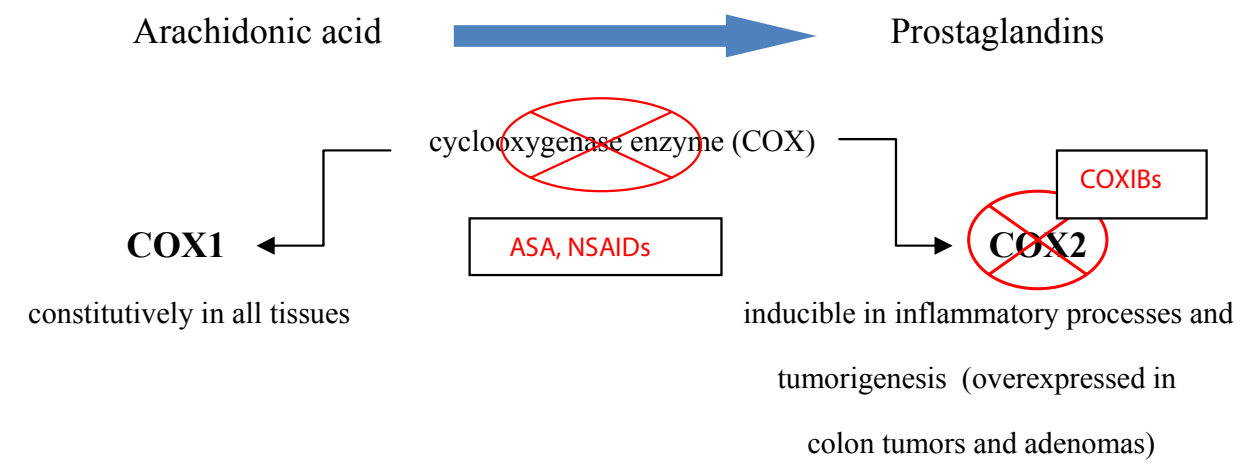

Figure 1: Scheme of the cyclooxygenase pathway.

COX-dependent mechanisms

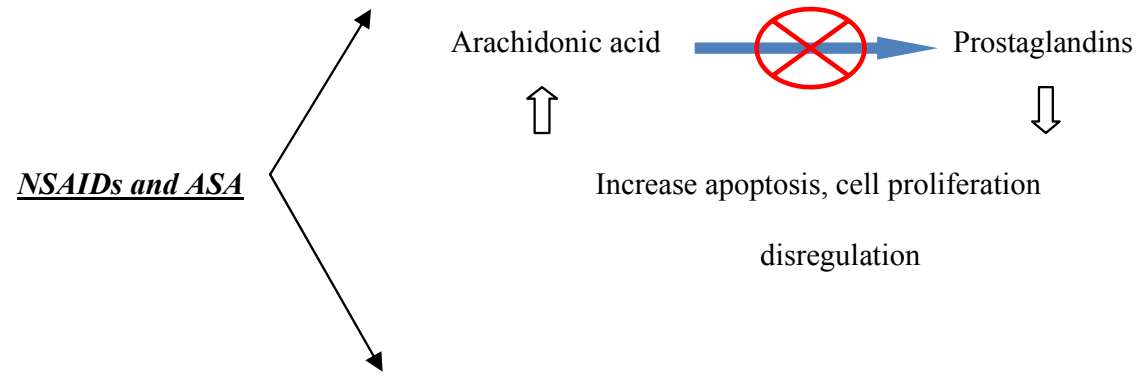

COX-independent mechanisms (not well understood)

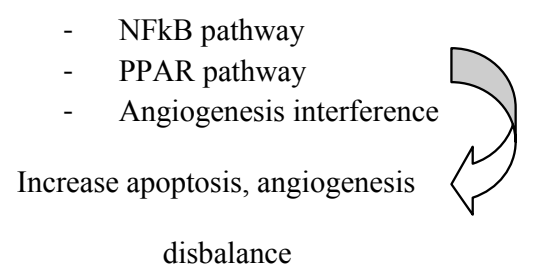

Figure 2: Scheme of COX-dependent and independent mechanism related with NSAID and ASA

These all mechanisms could be the main pathways through out salicylates and NSAIDs act as chemopreventive agents in colorectal cancer in the adenoma-carcinoma sequence.

This review will address the scientific evidence for these agents in sporadic CRC chemoprevention field.

\section{Aspirin (ASA)}

The role of ASA in chemoprevention was first provided by Kune et al. [6] in a case-control study in 1988, where an odds ratio (OR) of 0.53 for CRC incidence was observed for chronic users of aspirin compared with nonusers. Since the publication of this report, other epidemiological observational studies have shown similar results regarding the incidence of CRC and the development of adenomas.

In response to these studies, randomised trials were designed to evaluate the role of aspirin in preventing cancer. Two of the studies determined the incidence of CRC in large healthy populations and were unable to demonstrate a chemopreventive effect for ASA. The first was the Physicians' Health Study (PHS) [7], a blind, randomised study designed to test the effect of low doses of aspirin on the incidence of cardiovascular events and CRC. In 1993, Gann et al. [8] published the results of CRC incidence after 5 years of follow-up. In this study, 22071 healthy men were randomised to receive either placebo or $325 \mathrm{mg}$ of aspirin every other day. The primary endpoints of incidence of invasive CRC (RR 1.15, 95\% CI 0.80-1.65) and the incidence of adenomas (RR $0.85,95 \%$ CI 0.68-1.10) were both negative. In 1998, Stürmer et al. [9] published an update of these data over a 12-year period, demonstrating a lack of effect with an RR of 1.03 (95\% CI 0.83-1.28) for CRC incidence.

The second study, by Cook et al. [10] was published in 2005. In this study, 39876 healthy women were randomised to receive placebo or $100 \mathrm{mg}$ aspirin every other day. The endpoints of the study were to establish 1) the incidence of invasive cancer in any location and 2) the incidence of breast cancer, CRC and lung cancer. The study was unable to demonstrate an effect, with an RR of 1.01 for any cancer and an RR of 0.97 (95\% CI 0.77-1.24, p = 0.08) for CRC incidence.

In 2003, under the assumption that the dose used in these two studies was not optimal to test the power of ASA in chemoprevention, 


\begin{tabular}{|c|c|c|c|c|c|c|c|}
\hline Study & Year & Cohort & $\mathrm{N}^{\circ}$ cases & Intervention & End Point & RR & Result \\
\hline PHS (Gann) & 1993 & Healthy & 22071 & $\begin{array}{c}325 \text { mg every other day } \\
\text { vs. placebo }\end{array}$ & $\begin{array}{c}\text { CCR } \\
\text { incidence }\end{array}$ & $1.150 .80-1.65$ & Negative \\
\hline PHS (Stürmer) & 1998 & Healthy & 22071 & $\begin{array}{c}325 \text { mg every other day } \\
\text { vs. placebo }\end{array}$ & $\begin{array}{c}\text { CCR } \\
\text { incidence }\end{array}$ & $\begin{array}{c}1.03 \\
0.83-1.28\end{array}$ & Negative \\
\hline Cook et al. [10] & 2004 & Healthy & 39876 & 100 mg every other day & $\begin{array}{c}\text { CCR } \\
\text { incidence }\end{array}$ & $\begin{array}{c}0.97 \\
0.77-1.24\end{array}$ & Negative \\
\hline Baron et al. [11] & 2003 & Prior adenoma & 1121 & $\begin{array}{c}81 \mathrm{mg} \text { vs. } 325 \mathrm{mg} \text { daily } \\
\text { vs. placebo }\end{array}$ & $\begin{array}{l}\text { Adenomas } \\
\text { incidence }\end{array}$ & $\begin{array}{c}0.81 \\
0.69-0.96\end{array}$ & Positive for $81 \mathrm{mg}$ arm \\
\hline Sandler at al. [13] & 2003 & Prior CCR & 635 & $325 \mathrm{mg}$ daily vs. placebo & $\begin{array}{l}\text { Adenomas } \\
\text { incidence }\end{array}$ & $\begin{array}{c}0.65 \\
0.46-0.91\end{array}$ & Positive \\
\hline APPAC & 2003 & Prior adenoma & 272 & $\begin{array}{l}160 \text { mg vs. } 325 \text { mg vs. } \\
\text { placebo }\end{array}$ & $\begin{array}{l}\text { Adenomas } \\
\text { incidence }\end{array}$ & $\begin{array}{c}0.73 \\
0.52-1.04\end{array}$ & $\begin{array}{l}\text { Negative in } \\
\text { global }\end{array}$ \\
\hline
\end{tabular}

Table 1: Aspirin trials in sporadic CRC

\begin{tabular}{|c|c|c|c|c|c|c|}
\hline Study & Year & Cohort & No cases & Intervention & End Point & Result \\
\hline APPROVe & 2006 & Prior adenoma & 2587 & $\begin{array}{c}25 \text { mg rofecoxib vs. } \\
\text { placebo }\end{array}$ & $\begin{array}{c}\text { Adenoma } \\
\text { incidence }\end{array}$ & $\begin{array}{c}0.76 \\
0.69-0.83\end{array}$ \\
\hline APC & 2006 & Prior adenoma & 2035 & $\begin{array}{c}200 \text { mg bid vs. } 400 \mathrm{mg} \\
\text { bid vs. placebo }\end{array}$ & $\begin{array}{c}\text { Adenoma } \\
\text { incidence }\end{array}$ & $\begin{array}{c}0.67 \\
0.55\end{array}$ \\
\hline PreSAP & 2006 & Prior adenoma & 1561 & 400 mg once vs. placebo & $\begin{array}{c}\text { Adenoma } \\
\text { incidence }\end{array}$ \\
\hline
\end{tabular}

Table 2: COXIB trials in sporadic CRC

three studies were simultaneously published from selected populations (with the use of colonoscopy at baseline and follow-up). The main objective was to correlate the effect of different doses of ASA with the incidence of adenomas. The first study by Baron et al. [11] explored the effects of two doses of aspirin ( $81 \mathrm{mg}$ or $325 \mathrm{mg}$ twice daily) vs. placebo in 1121 patients with a recent history of adenomas. The study was positive for the primary endpoint (detection of one or more adenomas at first colonoscopy) at the $81 \mathrm{mg}$ dose (38\% vs. $47 \%$ in the placebo arm, $p=0.04)$. Moreover, the RR for the incidence of adenomas was 0.81 (95\% CI 0.69-0.96) with a 40\% reduced risk for advanced lesions at the $81 \mathrm{mg}$ dose. There was no statiscally significant difference in the risk of death or risk of bleeding compared with placebo.

In the second study, APPAC study, 272 patients with a personal history of colorectal adenomas were randomised to receive $160 \mathrm{mg}$ or $300 \mathrm{mg}$ of lysine acetylsalicylate or placebo for 4 years [12]. The study was not designed to study the differences between the two doses of salicylates and was negative at one year of follow-up with an RR of 0.73 (95\% CI 0.52-1.04, $\mathrm{p}=0.08)$ for the incidence of adenomas.

The third study, by Sandler et al., [13] was published in 2003. In this trial, 635 patients received placebo or $325 \mathrm{mg}$ ASA daily. It was closed prematurely after the first interim analysis, as the main objective was achieved. The incidence of 1 or more adenomas was 17 vs. $27 \%$ (p $=0.004$ ) with an RR of 0.65 . No significant differences in the size of polyps or incidence of advanced adenomas (larger than $1 \mathrm{~cm}$ or the presence of villous component) were found. The population in this study included patients with a personal history of CRC (Dukes A, B and $\mathrm{C}$ ), a high-risk population that may partially explain the results.

Subsequently, a meta-analysis of four studies (the three published in 2003 with an additional one published in 2008 [14] and positive for ASA) was published in 2009 [15]. In this study, with a population of 2698 and a median follow up of 33 months, the RR for the incidence of adenomas was 0.83 (95\% CI 0.72-0.96), and the incidence of advanced lesions was 0.72 (95\% CI from 0.57 to 0.90$)$. The number of CRCs diagnosed was low, with no statiscally significant difference compared with the placebo arm. Although the comparison between the low dose (450 patients) and the high dose (1228 patients) of aspirin appeared to show a greater effect for the lower doses, these data should be interpreted with caution due to the small number of trials included in the meta-analysis. Serious side effects were infrequent, and no difference in terms of gastrointestinal toxicity was noted. However, 12 individuals suffered from a stroke, all in the ASA group ( $\mathrm{p}=0.02)$.

The heterogeneity in terms of selection criteria, study population as well as dose and duration of treatment in the previous studies made it difficult to draw conclusions on the clinical use of ASA. The U.S. Preventive Services Task Force (USPSTF) conducted a meta-analysis, published in 2007, that included randomised trials, case-control and cohort studies [16]. This meta-analysis established an RR for adenoma incidence of 0.82 (95\% CI 0.7-0.95) and a decrease in CRC incidence of $22 \%$ (for the cohort studies). Mortality data were limited and inconsistent; thus, conclusions were not made. In terms of toxicity, the use of aspirin was associated with an increased risk in the incidence of gastrointestinal bleeding with an RR 1.5-3, which was dose dependent (higher for higher doses). In the analysis of the data, the benefit of aspirin was greater with higher doses compared with those used for cardiovascular prevention. Furthermore, the benefit was higher for the high-risk CRC population (family history) and for prolonged treatment.

Subsequent to this meta-analysis, few additional studies have been published. Only two studies, one by Flossmann et al. [17] and one by Rothwell et al. [18], provide data on prolonged treatment. Both studies, with 20-year follow-up in a population cohort from cardiovascular prevention studies (healthy population with no history of previous adenomas), studied CRC incidence as the primary endpoint. With 7588 and 14033 patients enrolled, respectively, and with different doses of aspirin $(30 \mathrm{mg}-1200 \mathrm{mg}$ ) for a median of 5-6 years, both studies demonstrate a benefit in CRC incidence with a similar HR ( 0.74 and 0.76 , respectively). When the analysis was separated by intervals of 10 years, the benefit of ASA occurred mainly in the second decade. The 
study by Rothwell et al. [18] also demonstrated a reduction in CRC mortality with a HR of 0.65 ( 0.48 to $0.88, \mathrm{p}=0.005)$. However, none of the initial studies were designed to study CCR incidence, as they were cardiovascular preventive studies conducted prior to the colonoscopy screening era. Thus, these data should be interpreted with caution.

Based on the data published to date, we can conclude that aspirin is effective in reducing adenomas and CRC incidence (modestly) and that its benefit is higher in high-risk populations, with an acceptable safety profile excluding risk populations for bleeding. It remains to be determined what the optimal dose and duration of treatment are and whether this strategy is associated with a reduction in CRC mortality with an acceptable toxicity profile for healthy individuals.

\section{Cyclooxygenase-2 Inhibitors (COXIBs)}

The selective inhibition of the COX2 isoform by COXIBs makes these drugs attractive for preventive studies to minimise side effects, such as the gastrointestinal toxicity observed with COX1 inhibition.

After data from approximately 40 observational studies demonstrated the utility of COXIBs as chemopreventive agents in patients with familial adenomatous polyposis [3], three randomised trials with similar designs (APPROVe, APC and PreSAP) were launched between 1999 and 2000. With a five-year follow-up, these studies examined the role of different COXIBs for three years in individuals with a recent history of adenomas. The main objective for all three studies was incidence of adenomas, with the secondary objectives of incidence of advanced adenomas (which included carcinoma in situ and invasive carcinoma) and the number and size of polyps. The three studies, despite being positive for its main objective, were closed early in 2004 after a safety analysis demonstrated an increase in cardiovascular events in some of them, leading to a withdrawal of rofecoxib from the market.

The APPROVe study, which randomised 2587 patients to receive placebo or $25 \mathrm{mg}$ of rofecoxib daily, showed an RR of 0.76 (95\% CI 0.69-0.83) for its main objective [19].The safety analysis of this study initiated the safety analysis of the others, after presenting an RR for cardiovascular events of 1.92 (1.19-3.11). In parallel, the APC trial comparing two doses of celecoxib (200 mg vs. $400 \mathrm{mg}$ twice daily) vs. placebo showed a reduction for adenoma incidence for the two doses studied (RR 0.67 for $200 \mathrm{mg}$ dose and 0.55 for $400 \mathrm{mg}$ dose) as well as a reduction for advanced adenoma incidence (RR 0.43 and RR 0.34, respectively) [20]. However, a significant increase in the incidence of cardiovascular events was again reported, with an RR of 2.6 and 3.4 for the low and high dose of celecoxib, respectively. After 5 years of follow-up, an update of the data was published in 2009. In it, the chemopreventive effect on adenoma incidence remained with celecoxib use, with an RR of 0.71 for the low dose and 0.62 for the high dose. However, the cardiovascular risk also remained, with an RR of 1.6 (1-2.5) for the $200 \mathrm{mg}$ dose and 1.9 (1.2-3.1) for the $400 \mathrm{mg}$ dose [21]. The last study, PreSAP trial, ran parallel to the APC [22]. It randomized 2:1 to receive $400 \mathrm{mg}$ single dose of celecoxib (933 patients) or placebo (628 patients). The RR for the primary endpoint was 0.64 , and 0.49 for advanced adenoma incidence; both significant. This study was also closed in 2004, although the data did not demonstrate an increase in cardiovascular events with an RR of 1.30 (0.65-2.62). Thirty-five patients died due to cardiovascular events or had an episode of heart failure, acute myocardial infarction or stroke (23 in the experimental group (2.5\%) and 12 in the placebo group (1.9\%). A single explanation responsible for the differences between the two trials of celecoxib in the rate of cardiovascular events does not exist, although the difference in dosage and method of administration may explain the differences.

The complete analysis of the cardiotoxicity and cardiovascular event incidence of these trials has been published in several articles $[23,24]$.

With all these data, in 2007, the USPSTF published a new metaanalysis of the use of NSAIDs and COXIBs in the chemoprevention field and developed its recommendations based on the analysis of the data published in randomised trials, cohorts and case-control studies [25].The meta-analysis confirmed the effectiveness of COXIBs in adenoma prevention (RR 0.72, CI 0.68-0.77) and advanced lesion incidence; however, the cardiovascular risk associated with their use prevented the recommendation of their use as chemopreventives except for special groups at high risk of CRC. There are no studies published regarding CRC incidence and mortality with these drugs.

Although there is a lack of comparative studies between ASA, NSAIDs and COXIBs, COXIBs appear to have a greater effect as chemopreventive agents in CRC. However, the major side effects of COXIBs, mainly cardiovascular, limit their use in healthy individuals.

\section{Non Steroidal Anti-inflammatory Drugs (NSAIDs)}

The data supporting the use of other NSAIDs as chemopreventive agents in CRC come from observational, cohort and case-control studies. The previously discussed Rostom's meta-analysis described a reduction in CRC incidence of $30-40 \%$ and a reduction in adenoma incidence of approximately 45-35\% with these drugs [25]. However, they maintain the gastrointestinal toxicity of aspirin, with an ulcer complication rate of $1.5 \%$ per year. Other meta-analyses have suggested that a cardiovascular toxicity profile comparable to that of COXIBs is present with NSAID use, especially in relation to dose and duration of treatment [26]. Therefore, the use of NSAIDs as chemopreventive agents currently is not recommended due to the potential toxic side effects.

The combination of different chemopreventive agents is an attractive strategy that would increase the effectiveness of these agents while minimising their side effects. In 2008, a study combining the use of sulindac (NSAID) and difluoromethylornithine (an inhibitor of polyamides synthesis) was published. The study yielded positive results in a population with a recent history of adenomas [27]. An RR of 0.30 (95\% CI 0.18-0.49) was obtained for its main objective (adenoma incidence); while a $92 \%$ reduction risk in advanced lesions with no significant differences in side effects was also observed. However, an analysis of cardiovascular safety was published a year later, and an increase in cardiovascular events was observed in subjects with cardiovascular risk factors (7 patients in the experimental arm vs. 1 patient in the placebo arm) [28]; thus, this strategy, while promising, requires additional studies with additional patients to draw conclusions.

\section{Conclusions}

Chemoprevention in sporadic CRC seems to be an attractive option to reduce cancer incidence and its mortality. Both ASA and COXIBs reduce adenoma incidence and, perhaps, they could have an effect in CRC development, however there is a lack of comparative trials between these agents. Dose and duration of treatment reminds 
Citation: Manzano A, Pérez-Segura P (2011) Chemoprevention in Sporadic Colorectal Cancer: The Role of Salycilates, Nsaids and Coxibs. J Cancer Sci Ther S3:005. doi:10.4172/1948-5956.S3-005

Page 5 of 5

to be determine and their safety profile may limit their use, mainly in healthy individuals. Thus, while promising, more long term trials are needed in order to set the role of these agents in this field.

\section{References}

1. Pisani P, Bray F, Parkin DM (2002) Estimates of the world-wide prevalence of cancer for 25 sites in the adult population. Int J Cancer 97: 72-81.

2. Jemal A, Siegel R, Ward E, Hao Y, Xu J, et al. (2009) Cancer Statistics, 2009. CA Cancer J Clin 59: 225-249.

3. Hawk ET, Levin B (2005) Colorectal cancer prevention. J Clin Oncol 23: 378391.

4. Chan TA (2002) Nonsteroidal anti-inflammatory drugs, apoptosis, and coloncancer chemoprevention. Lancet Oncol 3: 166-174.

5. Arber N (2008) Cyclooxygenase-2 inhibitors in colorectal cancer prevention: point. Cancer Epidemiol Biomarkers Prev 17: 1852-1857.

6. Kune GA, Kune S, Watson LF (1988) Colorectal cancer risk, chronic illnesses, operations, and medications: case control results from the Melbourne Colorectal Cancer Study. Cancer Res 48: 4399-4404.

7. Final report on the aspirin component of the ongoing Physicians' Health Study. Steering Committee of the Physicians' Health Study Research Group. N Engl J Med 312: 129-135

8. Gann PH, Manson JE, Glynn RJ, Buring JE, Hennekens CH (1993) Low-dose aspirin and incidence of colorectal tumors in a randomized trial. J Natl Cancer Inst 85: 1220-1224.

9. Stürmer T, Glynn RJ, Lee IM, Manson JE, Buring JE, et al. (1998) Aspirin use and colorectal cancer: post-trial follow-up data from the Physicians' Health Study. Ann Intern Med 128: 713-720.

10. Cook NR, Lee IM, Gaziano JM, Gordon D, Ridker PM, et al. (2005) Low-dose aspirin in the primary prevention of cancer: the Women's Health Study: a randomized controlled trial. JAMA 294: 47-55.

11. Baron JA, Cole BF, Sandler RS, Haile RW, Ahnen D, et al. (2003) A randomized trial of aspirin to prevent colorectal adenomas. N Engl J Med 348: 891-899.

12. Benamouzig R, Deyra J, Martin A, Girard B, Jullian E, et al. (2003) Daily soluble aspirin and prevention of colorectal adenoma recurrence: one-year results of the APACC trial. Gastroenterology 125: 328-36.

13. Sandler RS, Halabi S, Baron JA, Budinger S, Paskett E, et al. (2003) A randomized trial of aspirin to prevent colorectal adenomas in patients with previous colorectal cancer. N Engl J Med 348: 883-890.

14. Logan RF, Grainge MJ, Shepherd VC, Armitage NC, Muir KR; ukCAP Tria Group (2008) Aspirin and folic acid for the prevention of recurrent colorectal adenomas. Gastroenterology 134: 29-38.

15. Cole BF, Logan RF, Halabi S, Benamouzig R, Sandler RS, et al. (2009) Aspirin for the chemoprevention of colorectal adenomas: meta-analysis of the randomized trials. J Natl Cancer Inst 101: 256-266.

16. Dubé C, Rostom A, Lewin G, Tsertsvadze A, Barrowman N, Code C, (2007) The use of aspirin for primary prevention of colorectal cancer: a systematic review prepared for the U.S. Preventive Services Task Force. Ann Intern Med 146: 365-375.

17. Flossmann E, Rothwell PM; British Doctors Aspirin Trial and the UK-TIA Aspirin Trial (2007) Effect of aspirin on long-term risk of colorectal cancer: consistent evidence from randomised and observational studies. Lancet 369: 1603-1613.

18. Rothwell PM, Wilson M, Elwin CE, Norrving B, Algra A, et al. (2010) Long-term effect of aspirin on colorectal cancer incidence and mortality: 20 year follow-up of five randomized trials. Lancet 376: 1741-1749.

19. Baron JA, Sandler RS, Bresalier RS, Quan H, Riddell R, et al. (2006) A randomized trial of rofecoxib for the chemoprevention of colorectal adenomas. Gastroenterology 131: 1674-1682.

20. Bertagnolli MM, Eagle CJ, Zauber AG, Redston M, Solomon SD, et al. (2006) Celecoxib for the prevention of sporadic colorectal adenomas. $\mathrm{N}$ Engl $\mathrm{J}$ Med 355: $873-884$

21. Bertagnolli MM, Eagle CJ, Zauber AG, Redston M, Breazna A, et al. (2009) Five-year efficacy and safety analysis of the Adenoma Prevention with Celecoxib Trial. Cancer Prev Res 2: 310-321.

22. Arber N, Eagle CJ, Spicak J, Rácz I, Dite P, et al. (2006) Celecoxib for the prevention of colorectal adenomatous polyps. N Engl J Med 355: 885-895.

23. Bresalier RS, Sandler RS, Quan H, Bolognese JA, Oxenius B, et al. (2005) Cardiovascular events associated with rofecoxib in a colorectal adenoma chemoprevention trial. N Engl J Med 352: 1092-1102.

24. Solomon SD, McMurray JJ, Pfeffer MA, Wittes J, Fowler R, et al. (2005) Cardiovascular risk associated with celecoxib in a clinical trial for colorecta adenoma prevention. N Engl J Med 352: 1071-1080.

25. Rostom A, Dubé C, Lewin G, Tsertsvadze A, Barrowman N, et al. (2007) Nonsteroidal anti-inflammatory drugs and cyclooxygenase-2 inhibitors for primary prevention of colorectal cancer: a systematic review prepared for the U.S. Preventive Services Task Force. Ann Intern Med 146: 376-389.

26. Kearney PM, Baigent C, Godwin J, Halls H, Emberson JR, et al. (2006) Do selective cyclo-oxygenase-2 inhibitors and traditional non-steroidal antiinflammatory drugs increase the risk of atherothrombosis? Meta-analysis of randomised trials. BMJ 332: 1302-1308.

27. Meyskens FL Jr, McLaren CE, Pelot D, Fujikawa-Brooks S, Carpenter PM, et al. (2008) Difluoromethylornithine plus sulindac for the prevention of sporadic colorectal adenomas: a randomized placebo-controlled, double-blind trial Cancer Prev Res 1: 32-38.

28. Zell JA, Pelot D, Chen WP, McLaren CE, Gerner EW, et al. (2009) Risk of cardiovascular events in a randomized placebo-controlled, double-blind trial of difluoromethylornithine plus sulindac for the prevention of sporadic colorectal adenomas. Cancer Prev Res 2: 209-212. 